\title{
Resistance of Blast-Loaded Steel and Reinforced Concrete Beam-to-Column Connections
}

\author{
Alireza Bahrami ${ }^{1,2 *}$, Sina Matinrad ${ }^{2}$ \\ ${ }^{1}$ Department of Building Engineering, Energy Systems, and Sustainability Science, Faculty of Engineering and Sustainable \\ Development, University of Gävle, 80176 Gävle, Sweden. \\ ${ }^{2}$ Department of Civil Engineering, Abadan Branch, Islamic Azad University, Abadan, Iran.
}

Alireza Bahrami (corresponding author) ORCID: 0000-0002-9431-7820

ORCID: 0000-0003-0755-7074 (Sina Matinrad)

\begin{abstract}
Resistance of steel and reinforced concrete (RC) beam-tocolumn connections to blast loading is presented in this paper. The steel and RC connections are analysed nonlinearly using the finite element (FE) software ABAQUS. Comparisons of the obtained results from the connections modelling with those of the experimental tests reveal the modelling accuracy. Then, the ETABS software is utilised to design 4 buildings including 2 steel buildings with 5 and 9 storeys and 2 RC buildings with the same number of storeys. The components of the selected beam-to-column connections of the ground floor of the buildings are designed. Then, different parameters are considered for the nonlinear analyses of the steel and RC connections. The studied parameters for the steel connections are as the size of cross-section, bolts arrangement, and using stiffeners in the beam web of the connections, while the parameters for the RC connections are as the size of crosssection, stirrups space, and making beam non-prismatic in the beam-column connection region. It was found that increasing the cross-sectional sizes of the beams and columns of the steel and RC connections considerably enhances the resistance of the connections. In addition, change of the bolts arrangement in the steel connections and reducing the stirrups space in the $\mathrm{RC}$ connections significantly influence the resistance of the connections. However, using stiffeners in the beam web of the steel connections and making the beam non-prismatic in the region of the beam-column $\mathrm{RC}$ connections have no remarkable effect on the connections resistance. Failure modes of the connections are also evaluated.
\end{abstract}

Keywords: Steel, Reinforced Concrete, Connection, Blast, Reinforcement, Nonlinear Finite Element Analysis.

\section{INTRODUCTION}

Blasts can potentially damage the buildings considerably whether they are accidental or planned. The blast design was only taken into account for chemical facilities and military installations up to about the last fifty years. This issue was due to the high risk of accidental blasting that existed in these kinds of properties. The increasing number of terrorist threats during the past few decades has resulted in growing concerns about the resistance of industrial, commercial, and military buildings subjected to the blast loading [1]. One of the most preferred targets of terrorist attacks is lifeline structures. They mostly consider their targets as the places where human and economic losses are considerably large [2]. Terrorist attacks may lead to the loss and injury of many people and also to huge damages of structural and non-structural members of buildings which may result in the collapse of the entire building [3, 4]. Therefore, the blast resistance of buildings has become an essential issue for engineering communities [5].

Some researches have been conducted on the performance of steel and RC connections and also on the blast loading [6 - 24]. However, study on the resistance of steel and RC beam-tocolumn connections subjected to the blast loading is limited which has been presented in this paper.

This paper deals with the resistance of blast-loaded steel and RC connections. Applying the FE ABAQUS software, the connections are analysed nonlinearly. Verification of the modelling is done by comparison of the modelling results with those of the experimental tests. Two 5-storey steel and RC buildings and two 9-storey steel and RC buildings are designed using the ETABS software. Connections of the ground floor of the buildings are selected for the nonlinear analyses and their components are also designed. The nonlinear analyses of the connections are carried out considering different parameters. Effects of the parameters on the resistance of the connections are investigated. Failure modes of the connections are discussed.

\section{STEEL CONNECTIONS}

The steel beam-to-column connections are investigated in this section.

\subsection{EXPERIMENTAL TEST OF STEEL CONNECTION}

To demonstrate the modelling accuracy, an experimental test carried out on a steel connection [25] was modelled. The specimen details and its material properties are indicated in Fig. 1 and Table 1, respectively. The beam, column, T-sections, bolts, steel plates, and stiffeners are the components of the connection. The top and bottom flanges of the beam were connected to the column by the T-sections and the web of the beam was connected to the column by plates. In addition, two stiffeners were welded in the column web where the beam was connected to the column. The modulus of elasticity and the Poisson's ratio of the steel are $210 \mathrm{GPa}$ and 0.3 , respectively. 


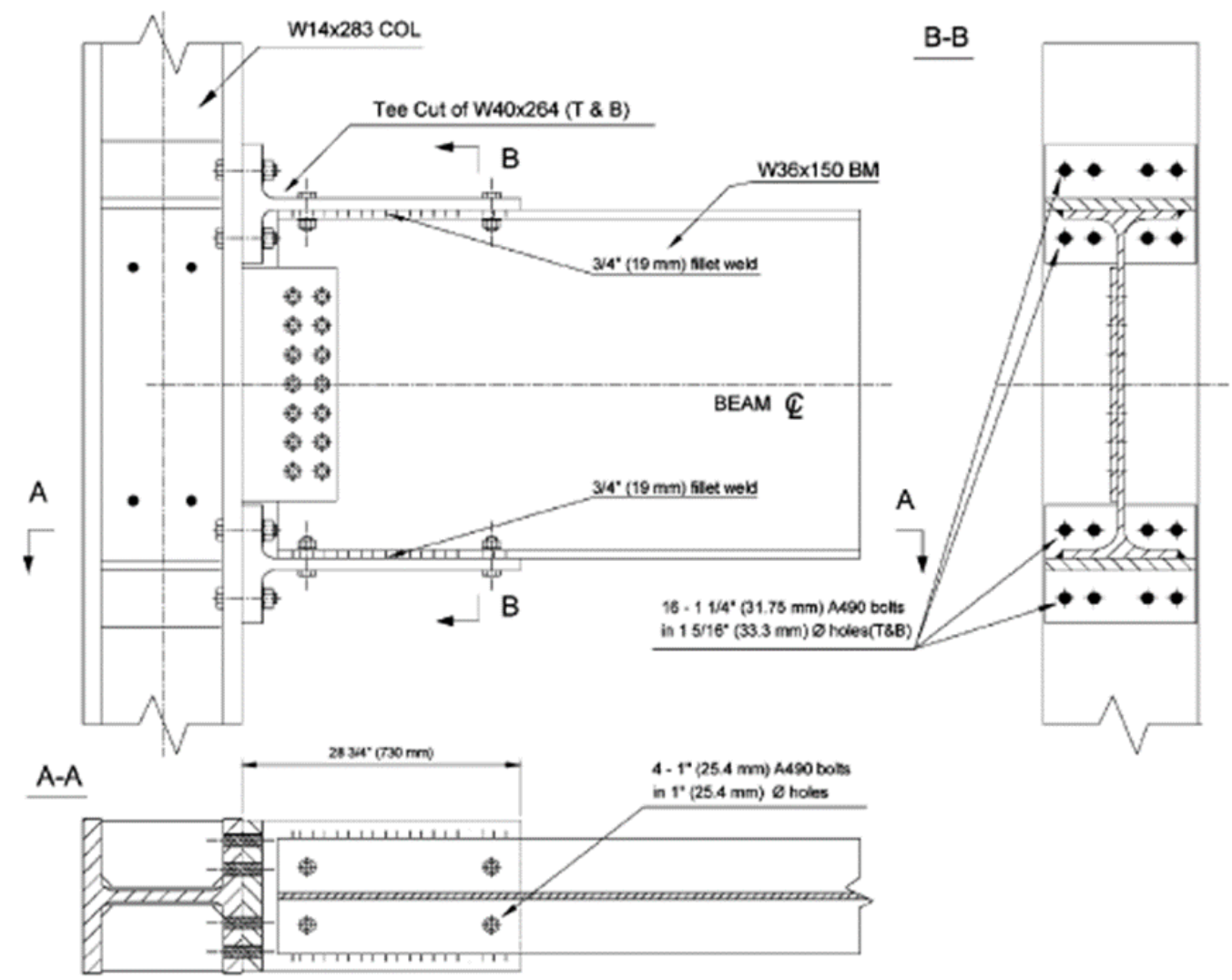

Fig 1. Details of tested specimen [25]

Table 1. Material properties

\begin{tabular}{|c|c|c|c|}
\hline $\begin{array}{c}\text { Component of } \\
\text { connection }\end{array}$ & $\begin{array}{c}\text { Yield stress } \\
(\mathrm{MPa})\end{array}$ & $\begin{array}{c}\text { Ultimate stress } \\
(\mathrm{MPa})\end{array}$ & Section \\
\hline Beam & 390 & 512.6 & $\mathrm{~W} 36 \times 150$ \\
\hline Column & 358.3 & 454.7 & $\mathrm{~W} 14 \times 283$ \\
\hline T-section & 441 & 544.3 & WT40×264 \\
\hline
\end{tabular}

\subsection{FINITE ELEMENT MODELLING OF STEEL CONNECTIONS}

All the specifications of the tested steel connection have been adopted in the FE modelling. The C3D8R solid element has been used for the model. It is an eight-node element with three degrees of freedom on each node. An essential part of the modelling is the material modelling [26, 27, 28]. The steel has been considered to have bilinear kinematic hardening behaviour to take into account progressive hardening and softening effects $[29,30]$. Tie was utilised to define the contact surface between the components of the connection which allows to combine two areas with different meshes. The displacement method was applied for the simulation of the loading. The boundary conditions of the experimental test have been modelled, too. The modelled steel connection is shown in Fig. 2. Mesh refinement has also been carried out for the modelling and a suitable mesh size which provided more accurate results was selected for the analysis of the connections.

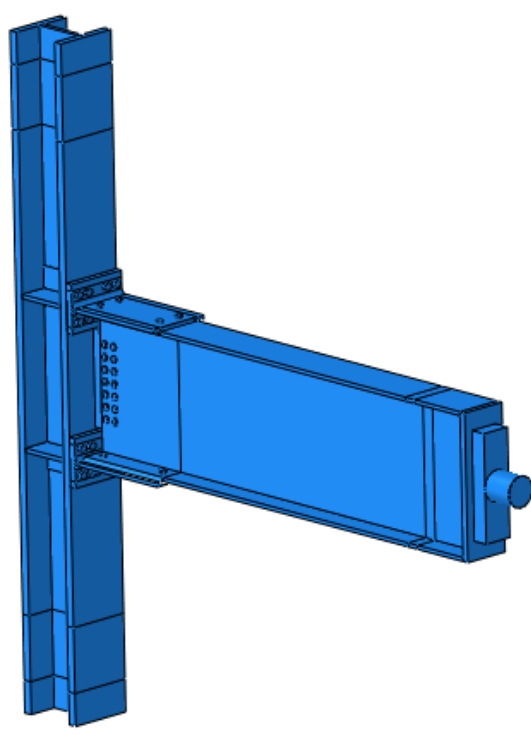

Fig 2. Modelled steel connection

Then, the force-displacement graph has been achieved from the nonlinear analysis of the modelled connection. The forcedisplacement graphs of the modelling and experimental test are compared with each other. It is found from Fig. 3 that the maximum strength obtained from the modelled specimen is $1622 \mathrm{kN}$ with the displacement of $129 \mathrm{~mm}$ while they are respectively as $1535 \mathrm{kN}$ and $132 \mathrm{~mm}$ for the tested specimen. This issue reveals the point that the ultimate strengths have the difference of only $5.4 \%$. In addition, comparison of the graphs 
from the behavioural point of view indicates that they are similar to each other. It uncovers the similar behaviour of the tested and modelled specimens under the loading.

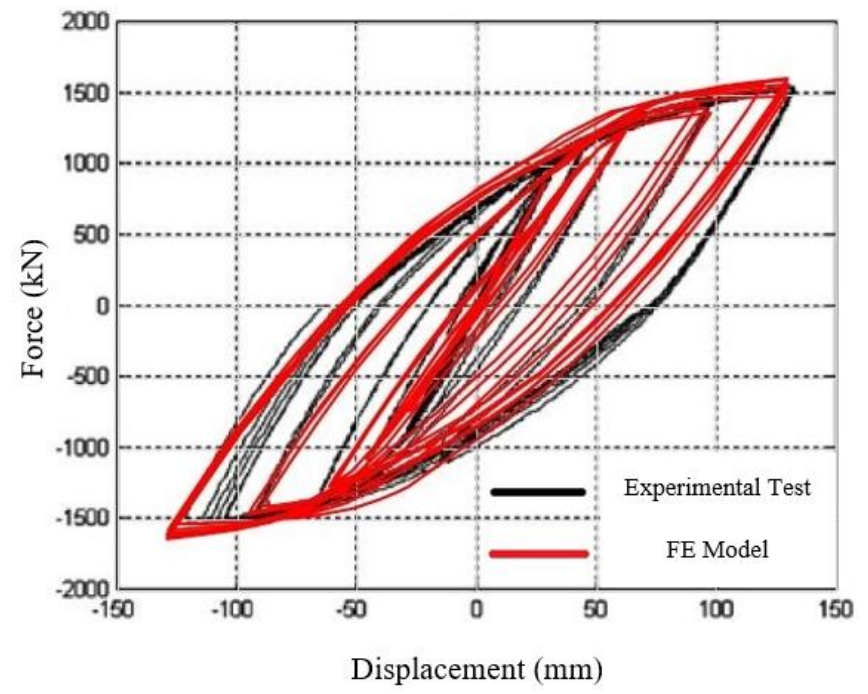

Fig 3. Comparison of graphs of modelled and experimentally tested steel connections

On the other hand, Figs. 4 and 5 illustrate the failure modes of the tested and modelled steel connections, respectively. As shown in the figures, there has been a gap between the beam and column of the connection, which corresponds to the high stress concentration on the connection. The figures clearly uncover that their failures are in a very good agreement with each other and they have similar failure modes.

Consequently, the small difference between the results obtained from the tested and modelled connections, their similar behaviours and failure modes reveal that the tested and modelled specimens agree well with each other and the accuracy of the modelling is demonstrated. Therefore, the proposed modelling is adopted for further analyses of the steel connections in order to investigate their resistance to the blast loading.

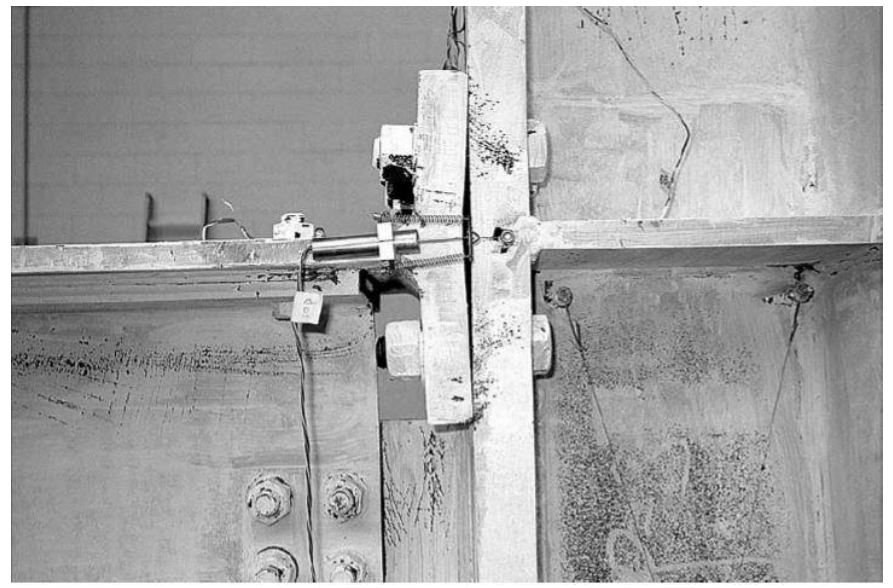

Fig 4. Failure mode of tested steel connection [25]

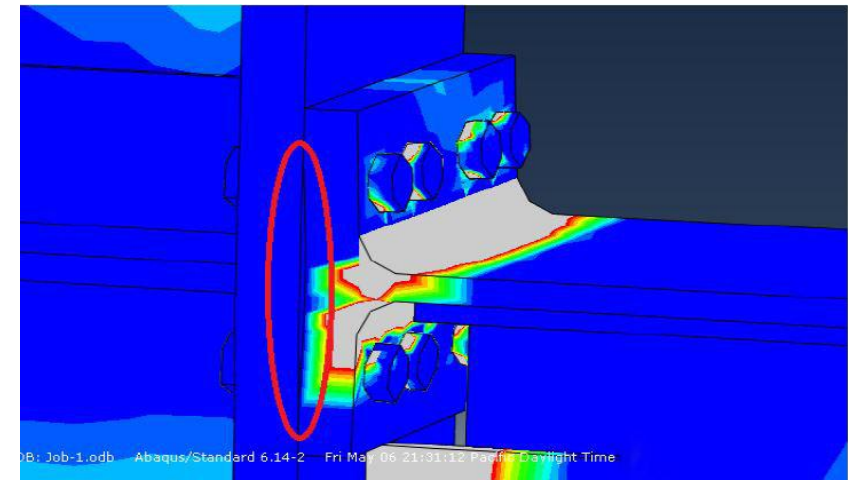

Fig 5. Failure mode of modelled steel connection

\subsection{BUILDING DESIGN}

Two steel buildings of 5 and 9 storeys with the storey height of $3 \mathrm{~m}$ and equal spans of $4 \mathrm{~m}$ in both planar directions perpendicular to each other have been designed based on AISC 360-10 employing the ETABS software in order to design the connections. Fig. 6 presents the typical designed building.

The ground floor of the buildings is the most critical floor against the surface blast loading because of its proximity to the blast centre. Accordingly, connections from the ground floor have been selected for the analyses.

\subsection{NONLINEAR ANALYSIS OF STEEL CONNECTIONS}

The components of the selected connections of 5 and 9-storey steel buildings have been designed using the ETABS results. Tables 2 and 3 summarise the profiles utilised for the beams and columns of the buildings. The steel type ST37 with the Poisson's ratio of 0.3 has been considered for all the beams and columns of the buildings. Figs. 7-9 show the components of the designed connection for the 9-storey building. Specifications of all the bolts comply with ASTM A490.

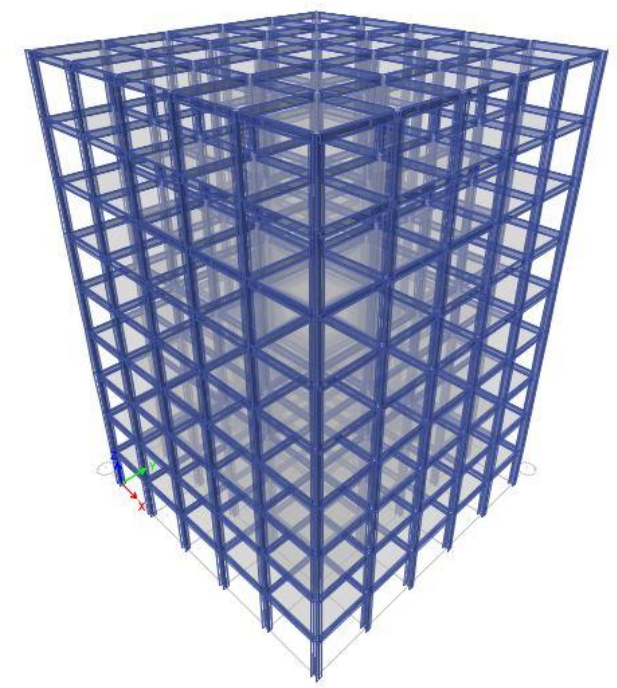

Fig 6. Designed 9-storey building 
International Journal of Engineering Research and Technology. ISSN 0974-3154, Volume 13, Number 1 (2020), pp. 12-27

(C) International Research Publication House. https://dx.doi.org/10.37624/IJERT/13.1.2020.12-27

Table 2. Specifications of beams and columns in 5-storey steel building

\begin{tabular}{|c|c|}
\hline Member & Specification \\
\hline Beam & $\mathrm{W} 12 \times 16$ \\
\hline Column & $\mathrm{W} 12 \times 87$ \\
\hline
\end{tabular}

Table 3. Specifications of beams and columns in 9-storey steel building

\begin{tabular}{|c|c|}
\hline Member & Specification \\
\hline Beam & W16×26 \\
\hline Column & W14×159 \\
\hline
\end{tabular}

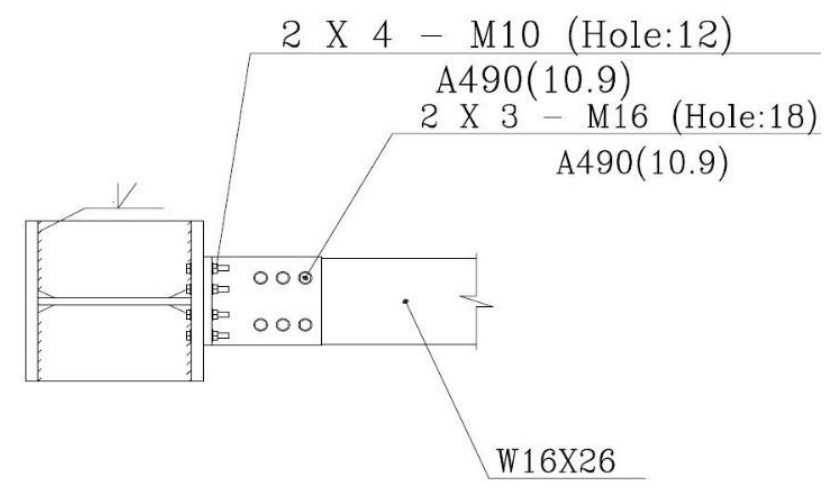

Fig 7. Plan view of steel connection (dimensions are in $\mathrm{mm}$ )

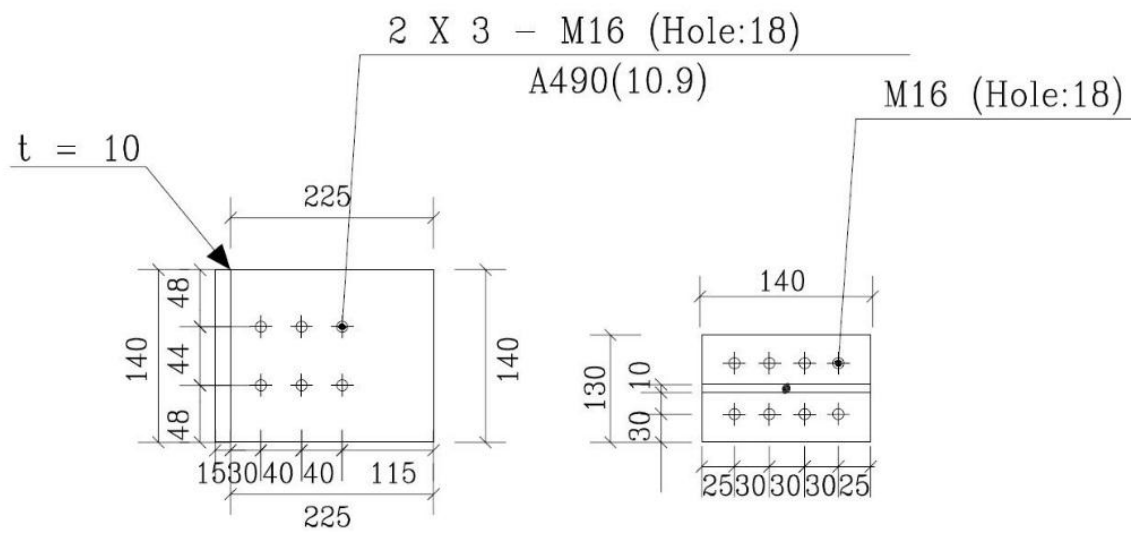

Fig 8. Details of T-section connecting beam flange to column flange in steel connection (dimensions are in mm)

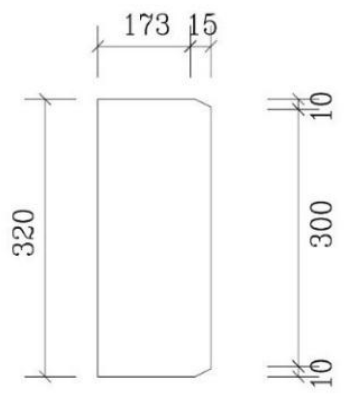

Fig 9. Column stiffeners (dimensions are in $\mathrm{mm}$ )

All the pre-mentioned details and features have been taken into account in the simulation of the steel connection utilising the ABAQUS software.

The Conwep method has been used to apply blast loads in ABAQUS. The Conwep method has high accuracy in calculating the effect of an explosion on a target on the basis of the distance between them and the mass equivalent to the explosive. To employ it, it is needed to introduce the software the explosion centre, the surface on which the explosion pressure should be applied, and the weight of the explosive as 
the TNT equivalent mass. TNT is usually considered as the reference for other explosives meaning when a strong explosive is other than TNT, its equivalent energy is achieved utilising the coefficient of the explosive defined as following:

$$
\text { C.F }=\frac{\text { explosive mass }}{\text { TNT equivalent mass }}
$$

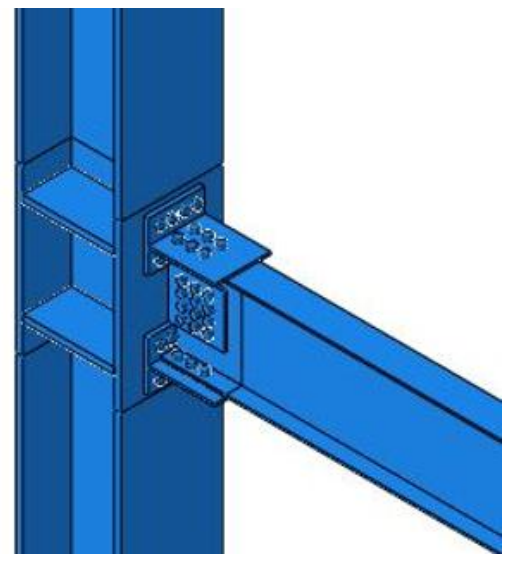

S1 connection

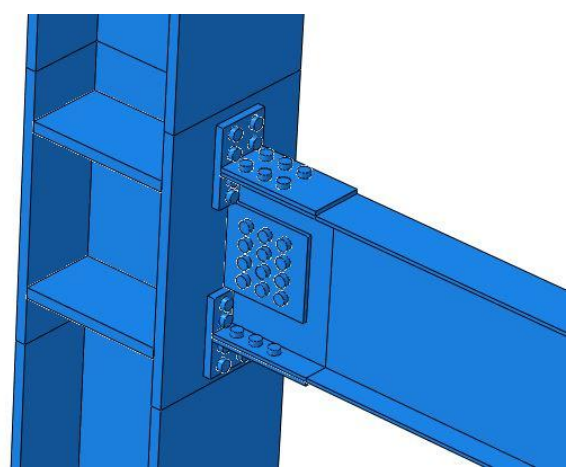

S3 connection

\subsection{RESULTS AND DISCUSSIONS OF NONLINEAR ANALYSIS OF STEEL CONNECTIONS}

In this section, 4 steel connections have been designed and modelled to study the effect of different parameters on the behaviour of the connections under the blast loading (Fig. 10). $\mathrm{S} 1$ and $\mathrm{S} 2$ are the steel connections for 5 and 9-storey buildings, respectively. S3 is similar to $\mathrm{S} 1$ with different bolt arrangements. S4 is also similar to S1 while it has stiffeners in the beam web with $40 \mathrm{~cm}$ distance from the column flange. The features of S1-S4 are the same as those explained in the previous section.

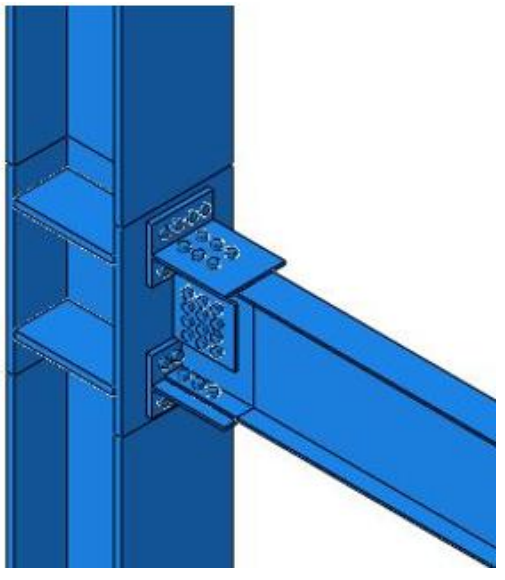

S2 connection

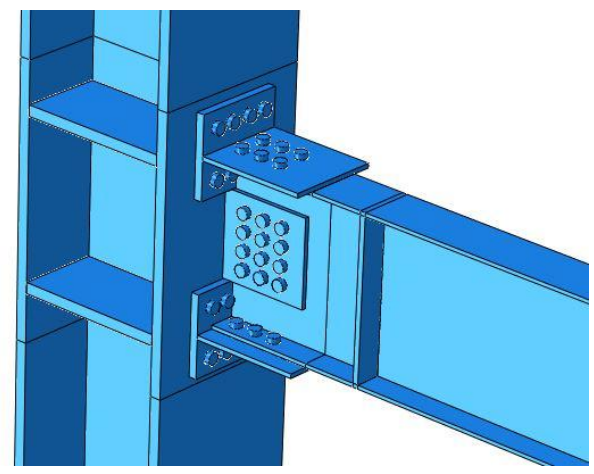

S4 connection

Fig 10. Modelled steel connections

\subsubsection{Effect of Size of Cross-Section on Steel Connections}

In order to investigate the effect of the size of cross-section on the connections, the connections S1 and S2 have been subjected to the blast load of $1000 \mathrm{~kg}$ TNT at $5 \mathrm{~m}$ distance from them. Figs. 11-14 indicate the obtained time-displacement graphs of the beams end perpendicular to the blast load and in line with the blast load for S1 and S2.

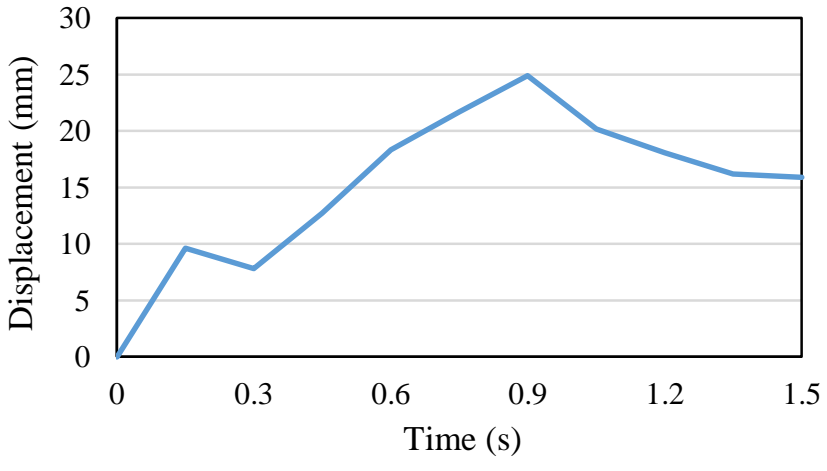

Fig 11. Displacement-time graph of $S 1$ beam end perpendicular to blast load 


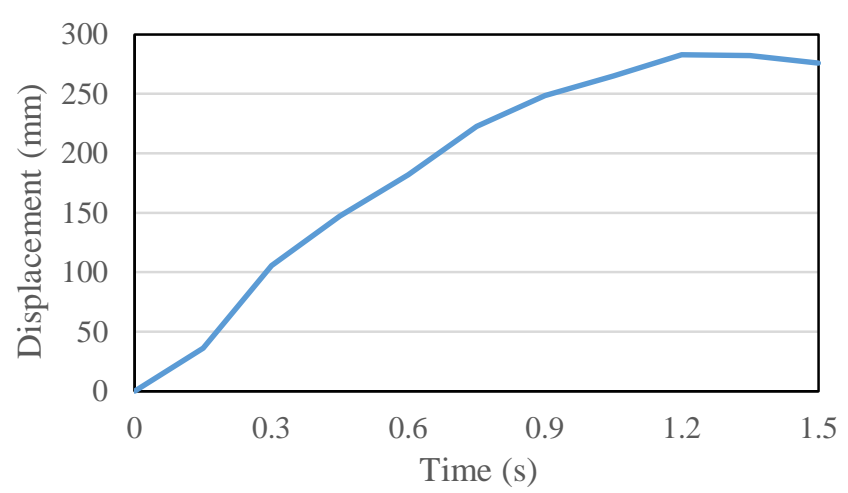

Fig 12. Displacement-time graph of $S 1$ beam end in line with blast load

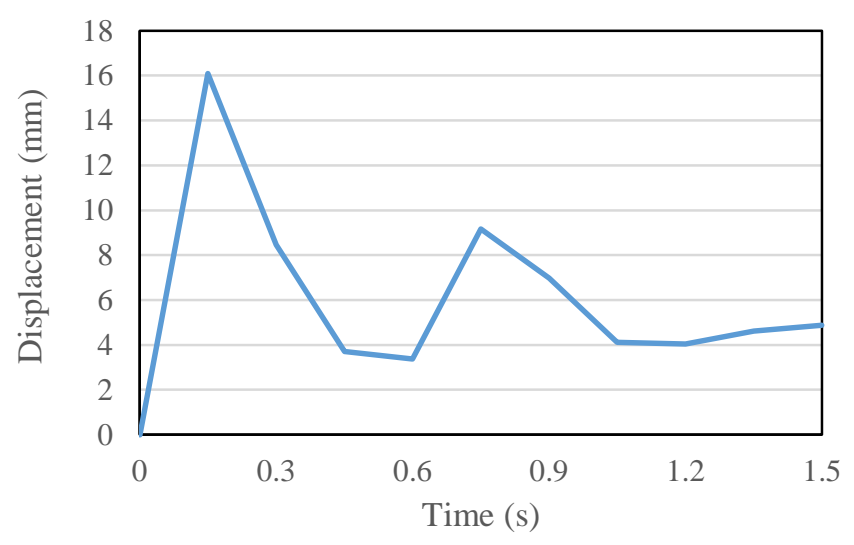

Fig 13. Displacement-time graph of $\mathrm{S} 2$ beam end perpendicular to blast load

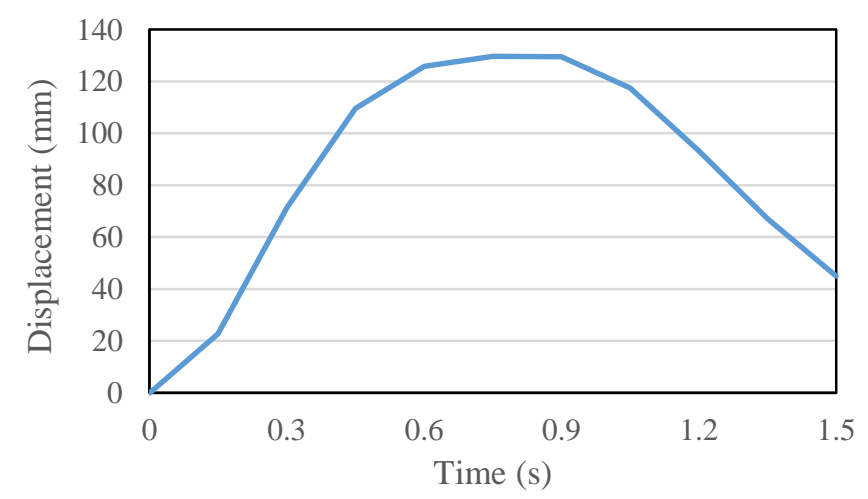

Fig 14. Displacement-time graph of $S 2$ beam end in line with blast load

Table 4 lists the maximum displacements of the end of the beams caused by blasting $1000 \mathrm{~kg}$ TNT at $5 \mathrm{~m}$ distance which have been obtained from Figs. 11-14. Considering the table and figures it can be observed that the maximum displacement occurred in line with the blast load, so that the maximum displacement of S1 model in line with the blast load is 11 times larger than that perpendicular to the blast load, however, this displacement difference for $\mathrm{S} 2$ model is more than 8 times.
Also, the maximum displacement of S2 in line with the blast load shows 54\% decrease compared with that of S1. However, the maximum displacement of S2 perpendicular to the blast load reduces $36 \%$ in comparison with that of $\mathrm{S} 1$. Because, as the beam and column cross-sections increase, their moment of inertia and stiffness improve, both of which have a large effect on the resistance to the blast load. The same process has witnessed in the connections responses, so that increasing the sizes of the cross-sections of the beam and column decreases the displacement of the beam.

Table 4. Maximum displacement of beam end due to blast load

\begin{tabular}{|c|c|c|}
\hline Connection & $\begin{array}{c}\text { Displacement } \\
\text { perpendicular to } \\
\text { blast load (mm) }\end{array}$ & $\begin{array}{c}\text { Displacement in } \\
\text { line with blast load } \\
(\mathrm{mm})\end{array}$ \\
\hline S1 & 25 & 283 \\
\hline S2 & 16 & 130 \\
\hline
\end{tabular}

\subsubsection{Effect of Bolts Arrangement on Steel Connections}

To investigate the effect of bolts arrangement on the connections, the connections S1 and S3 have been placed against the blast load of $1000 \mathrm{~kg}$ TNT at $5 \mathrm{~m}$ distance from them. Figs. 15 and 16 illustrate the obtained time-displacement graphs of the S3 beam end respectively perpendicular to the blast load and in line with the blast load.

Since the parameters such as vertical displacement of the beam and displacement in line with the blast load are effective parameters of the connection performance subjected to the blast loading, comparing Figs. 15 and 16 respectively with Figs. 11 and 12 demonstrates that by changing the arrangement of the bolts, the beam displacement is extremely increased whether in line with the blast load or perpendicular to the blast load.

Also, by comparing the displacement graphs perpendicular to the blast load for S1 (Fig. 11) and S3 (Fig. 15), it is found that in $\mathrm{S} 3$ due to the complete failure of the connection and its intolerance of the blast force, the displacement of the beam continues to develop its increasing trend even at about 1.5 seconds, so that the beam becomes completely separated from the column.

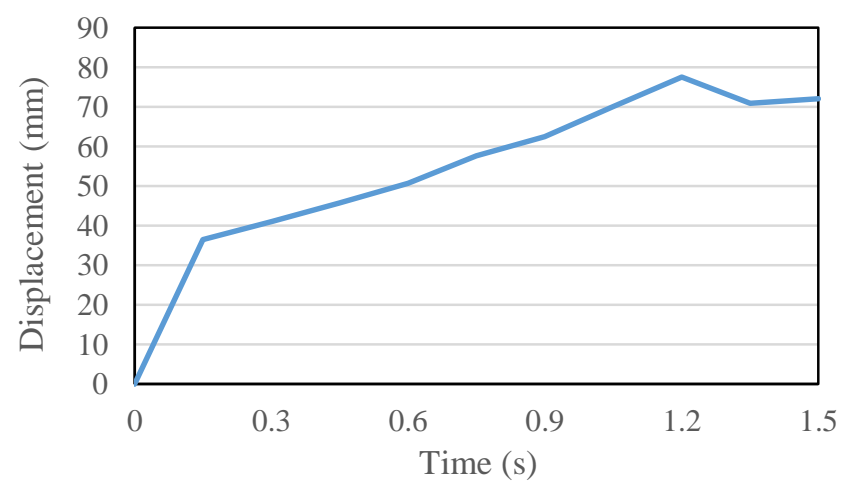

Fig 15. Displacement-time graph of S3 beam end perpendicular to blast load 


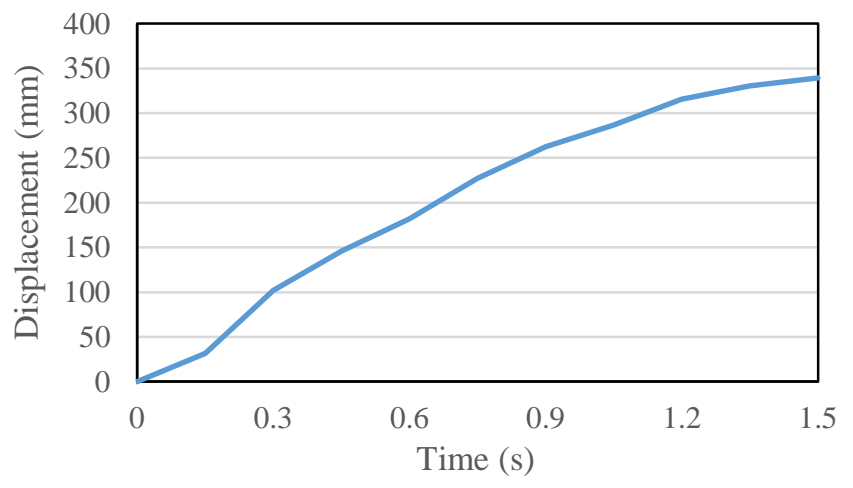

Fig 16. Displacement-time graph of $\mathrm{S} 3$ beam end in line with blast load

The maximum displacements of the beams end caused by the blasting $1000 \mathrm{~kg}$ TNT at $5 \mathrm{~m}$ distance are listed in Table 5 which have been obtained from Figs. 11-14 and 15-16. According to the figures and the table, it is found that the maximum displacement perpendicular to the blast load in S3 is more than three times larger than that of S1. Also, the displacement of the beam end in line with the blast load for S1 is reduced by $18 \%$ compared with that of $\mathrm{S} 3$.

Table 5. Maximum displacement of beam end due to blast load

\begin{tabular}{|c|c|c|}
\hline Connection & $\begin{array}{c}\text { Displacement } \\
\text { perpendicular to blast } \\
\text { load (mm) }\end{array}$ & $\begin{array}{c}\text { Displacement in } \\
\text { line with blast load } \\
(\mathrm{mm})\end{array}$ \\
\hline S1 & 25 & 283 \\
\hline S3 & 78 & 345 \\
\hline
\end{tabular}

Consequently, the results reveal that changing the bolts arrangement of the steel connections has a great effect on their blasting resistance.

\subsubsection{Effect of Using Stiffener in Beam Web on Steel Connections}

The connections S1 and S4 have been put against the blast load of $1000 \mathrm{~kg}$ TNT at $5 \mathrm{~m}$ distance from them to evaluate the effect of beam stiffeners on the resistance of the connections. The obtained displacement-time graphs of the beam end of S4 are presented in Figs. 18 and 19 with their maximum displacement values summarised in Table 6 .

From the comparison of Figs. 11 and 12 respectively with Figs. 17 and 19 and considering Table 6 it can be seen that the use of stiffener in the beam web results in a very small decrease of the displacement perpendicular to blast load and displacement in line with the blast load. Also, utilising the stiffener does not have a significant effect on the displacement from the behavioural viewpoint. Consequently, using the stiffeners does not remarkably influence the connection responses.

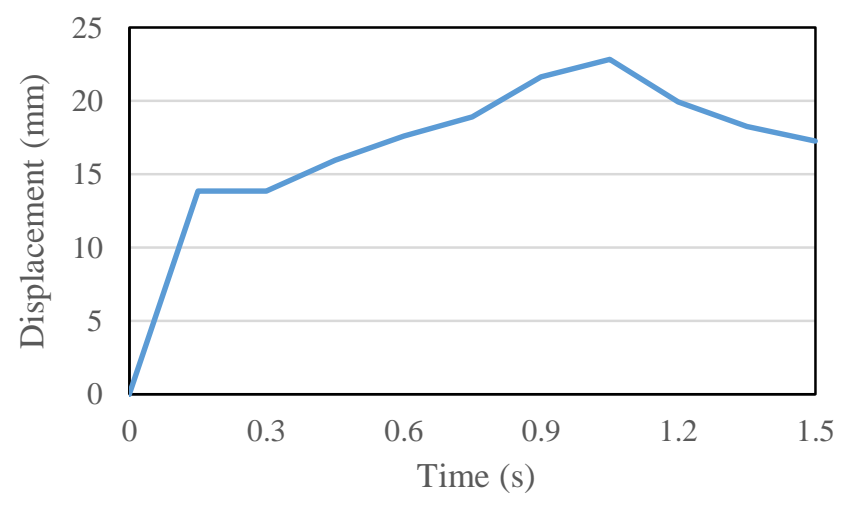

Fig 17. Displacement-time graph of S4 beam end perpendicular to blast load

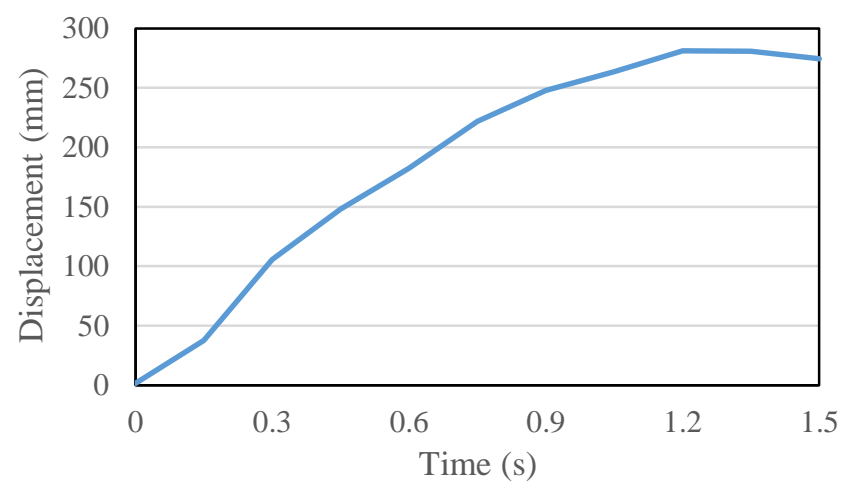

Fig 18. Displacement-time graph of $S 4$ beam end in line with blast load

Table 6. Maximum displacement of beam end due to blast load

\begin{tabular}{|c|c|c|}
\hline Connection & $\begin{array}{c}\text { Displacement } \\
\text { perpendicular to blast } \\
\text { load (mm) }\end{array}$ & $\begin{array}{c}\text { Displacement } \\
\text { in line with blast } \\
\text { load (mm) }\end{array}$ \\
\hline S1 & 25 & 283 \\
\hline S4 & 23 & 281 \\
\hline
\end{tabular}

\subsubsection{Failure Modes of Steel Connections}

Typical failure modes of the steel connections under the blast load are presented in Fig. 19. Due to the effect of the blast load on the connections, the stress concentration is observed on the connections. In S1, the stress concentration is found around the connection region. Also, the bolts of $\mathrm{S} 1$ have almost reached the plastic deformation owing to the low capacity of its 
components. Moreover, in S3, the connection has a plastic deformation and the stress concentration on the connection is greater than that of $\mathrm{S} 1$ which is due to its different bolt arrangements. Meanwhile, comparing the failure modes of S4 and S1 concludes that the use of the stiffener does not significantly influence the stress in the connection region.

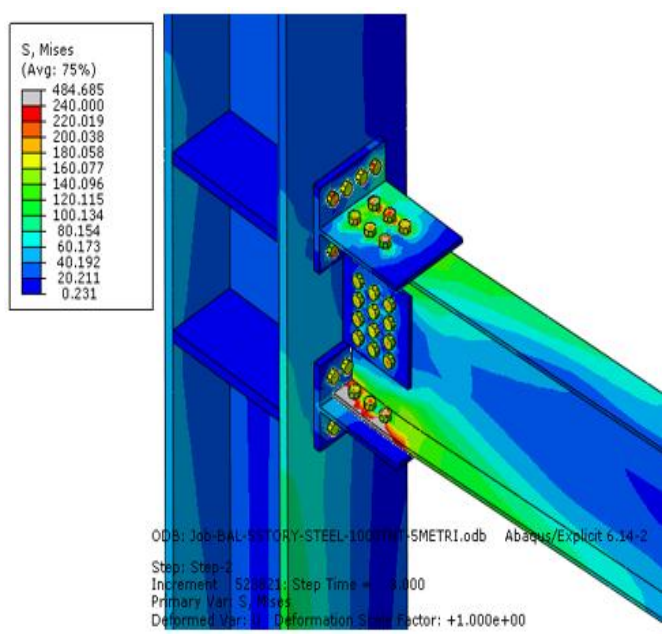

S1 connection

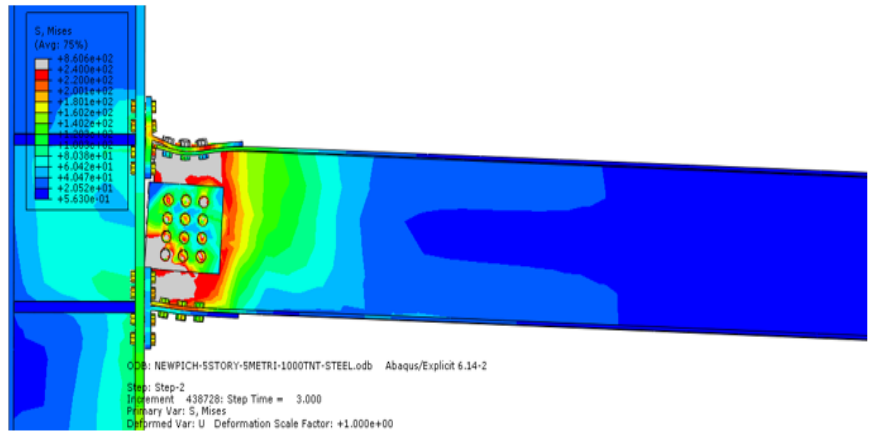

S3 connection

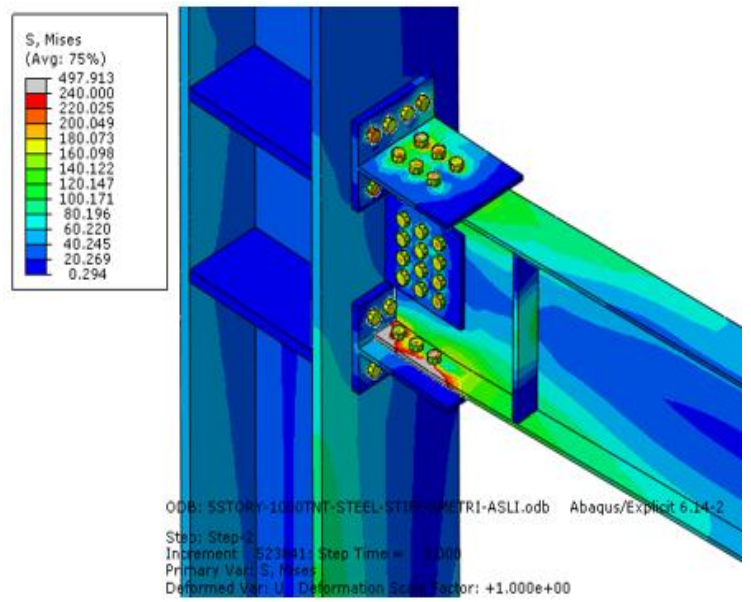

S4 connection

Fig 19. Typical failure modes of steel connections

\section{RC CONNECTIONS}

This section deals with the evaluation of the RC beam-tocolumn connections.

\subsection{EXPERIMENTAL TEST OF RC CONNECTION}

To verify the $\mathrm{FE}$ modelling of the $\mathrm{RC}$ connections, an experimental test of an RC connection [31] has been considered. Details of the tested specimen are shown in Fig. 20.
The yield stress of the longitudinal reinforcements of the beam and column is $507 \mathrm{MPa}$ and the yield stress of their stirrups is $384 \mathrm{MPa}$. The modulus of elasticity of the reinforcements is $200 \mathrm{GPa}$. Poisson's ratios of the concrete and reinforcements are 0.2 and 0.3 , respectively. 


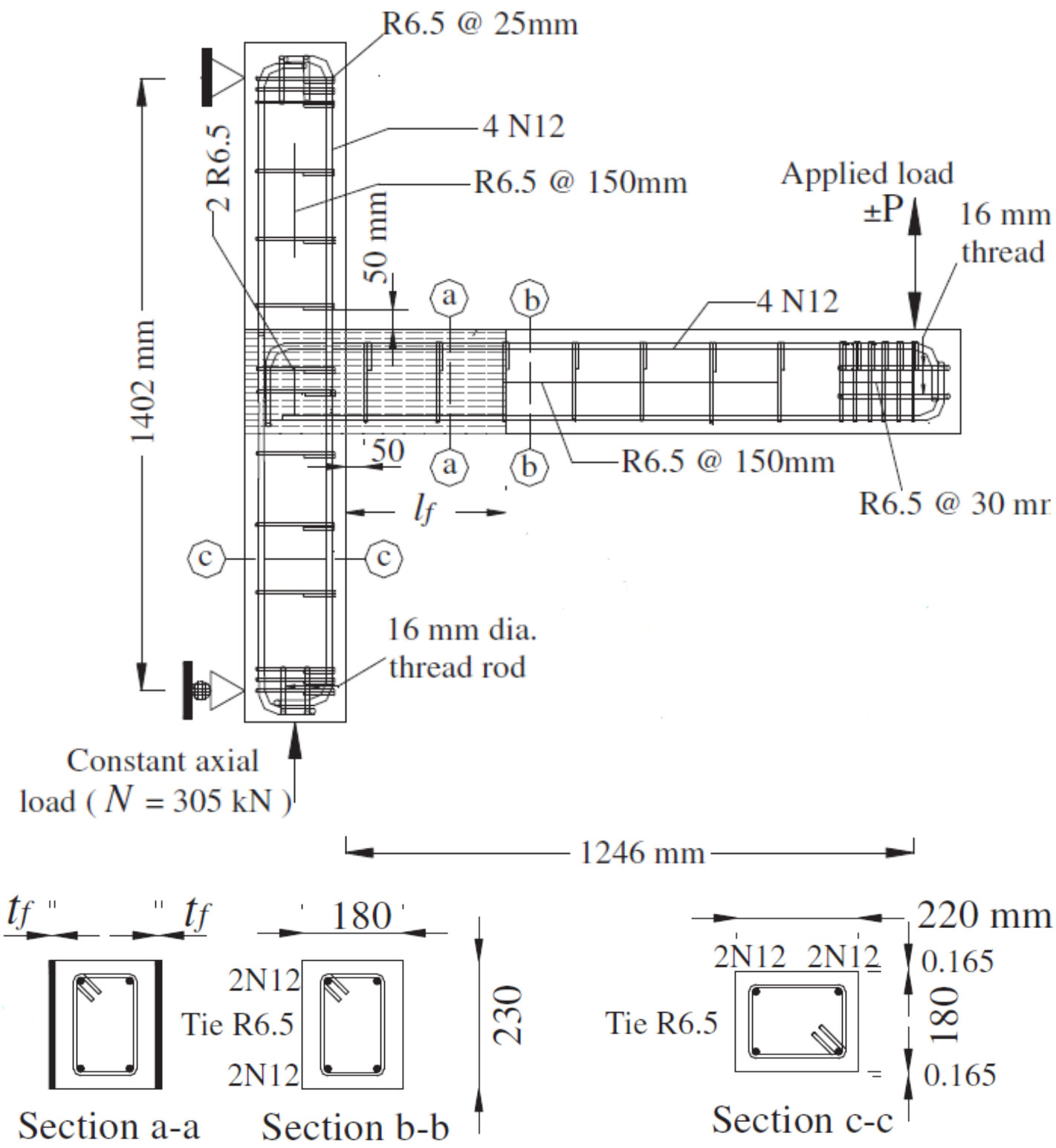

Fig 20. Details of experimentally tested specimen [31]

\subsection{FINITE ELEMENT MODELLING OF RC CONNECTIONS}

The mechanical properties of the concrete and steel materials of the experimental test have exactly been simulated in the modelling. The bilinear kinematic hardening behaviour has been considered for the steel material. To model the concrete, the three-dimensional concrete damage plasticity model has been used. The solid element C3D8R was employed in order to model the concrete. The truss element T3D2 was utilised to model the longitudinal and transverse reinforcements. The Embedded Region has been applied for the contact surface between the concrete and reinforcements. The loading and boundary conditions of the experimental test have precisely been simulated in the modelling. From the convergence study, the mesh size which led to more exact results was selected for the modelling. The simulated RC connection is illustrated in
Figs. 21 and 21.

The result obtained from the modelling is compared with the experimental test result as the force-displacement graphs. It can be observed from Fig. 23 that the ultimate strength of the experimentally tested specimen is $24.6 \mathrm{kN}$ with the displacement of $72 \mathrm{~mm}$ while they are respectively as $24.8 \mathrm{kN}$ and $70 \mathrm{~mm}$ for the simulated model. Consequently, the comparison reveals the only difference of less than $1 \%$ between them. Moreover, it is obvious from the figure that the graphs behave similarly. Thus, the very small difference between the results from the modelling and experimental test and their similar behaviour demonstrate the accuracy of the FE modelling of the RC connection. Therefore, the proposed FE modelling has been used to predict the behaviour of the RC connections. 


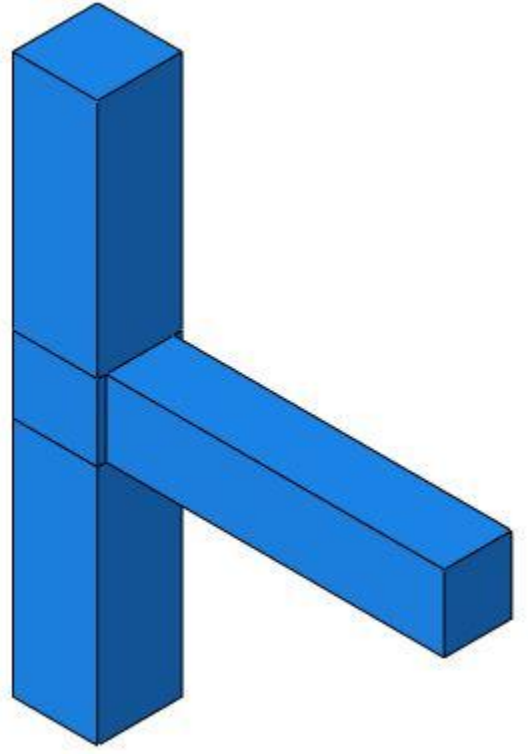

Fig 21. Modelled RC connection

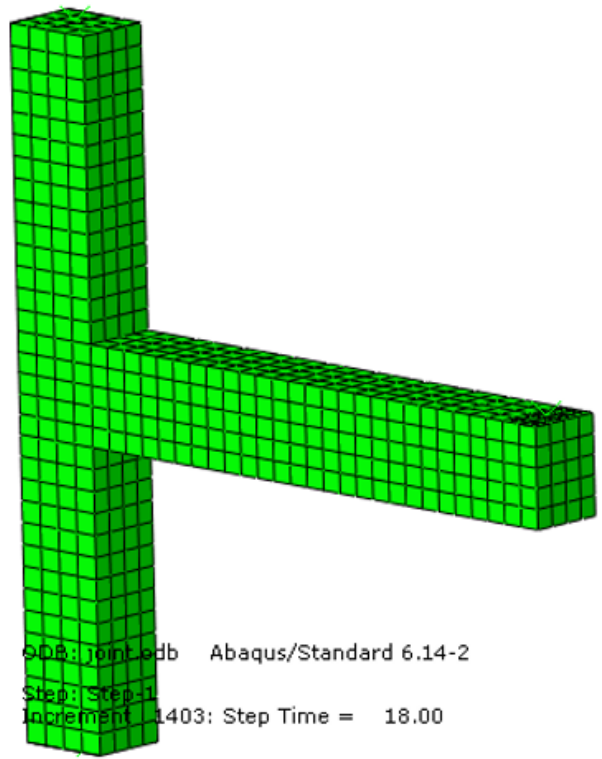

Fig 22. Modelled RC connection after meshing

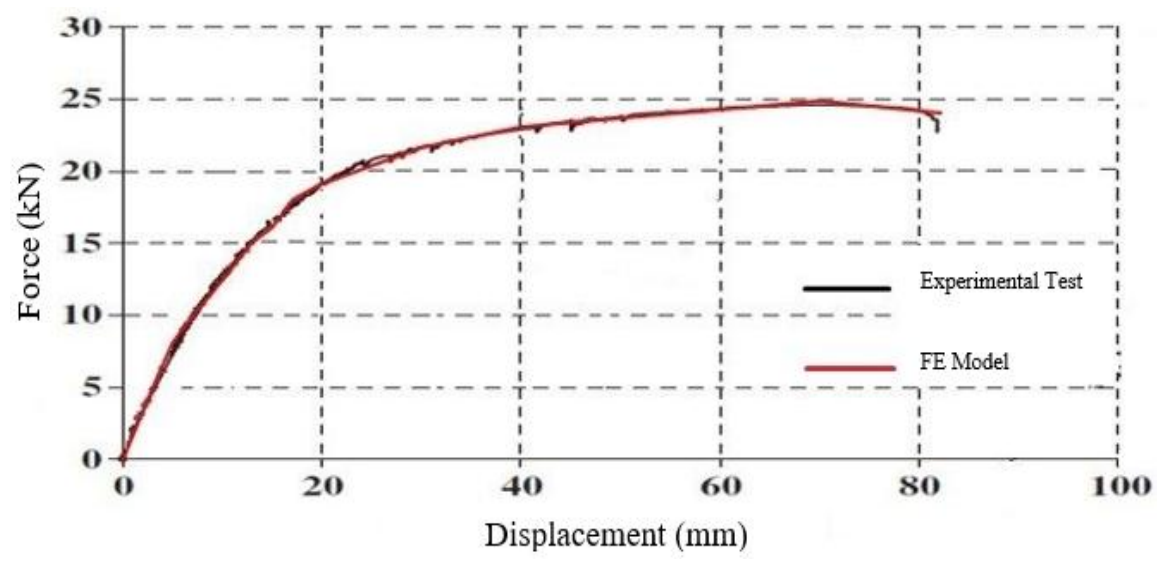

Fig 23. Comparison of obtained results from FE modelling and experimentally tested specimen

\subsection{BUILDING DESIGN AND NONLINEAR ANALYSIS OF RC CONNECTIONS}

Two 5 and 9-storey RC buildings have been designed with the same height and spans mentioned in the section 2.3 of this paper based on ACI 318-10 using the ETABS software. The ETABS results have been utilised to design the components of the selected connections in the ground floor of the buildings. The number and size of longitudinal reinforcements and stirrups have been determined based on the code ACI 318-10 utilising the ETABS results. Details of the designed RC connection are shown in Fig. 24. Specifications of the beams and columns of the buildings have been summarised in Tables 7 and 8. Poisson's ratios of the concrete and reinforcements have been adopted as 0.2 and 0.3 , respectively. The pre-mentioned specifications have also been considered in the simulation of the RC connections using ABAQUS.
Table 7. Specifications of RC connection in 5-storey building

\begin{tabular}{|c|c|c|}
\hline Member & Size $(\mathrm{cm})$ & Reinforcement $(\mathrm{mm})$ \\
\hline Beam & $40 \times 45$ & $4 \phi 16$ (longitudinal reinforcement) \\
$\phi 10$ (stirrup)
\end{tabular}

Table 8. Specifications of RC connection in 9-storey building

\begin{tabular}{|c|c|c|}
\hline Member & Size $(\mathrm{cm})$ & Reinforcement $(\mathrm{mm})$ \\
\hline Beam & $50 \times 55$ & $4 \phi 18$ (longitudinal reinforcement) \\
$\phi 10$ (stirrup)
\end{tabular}




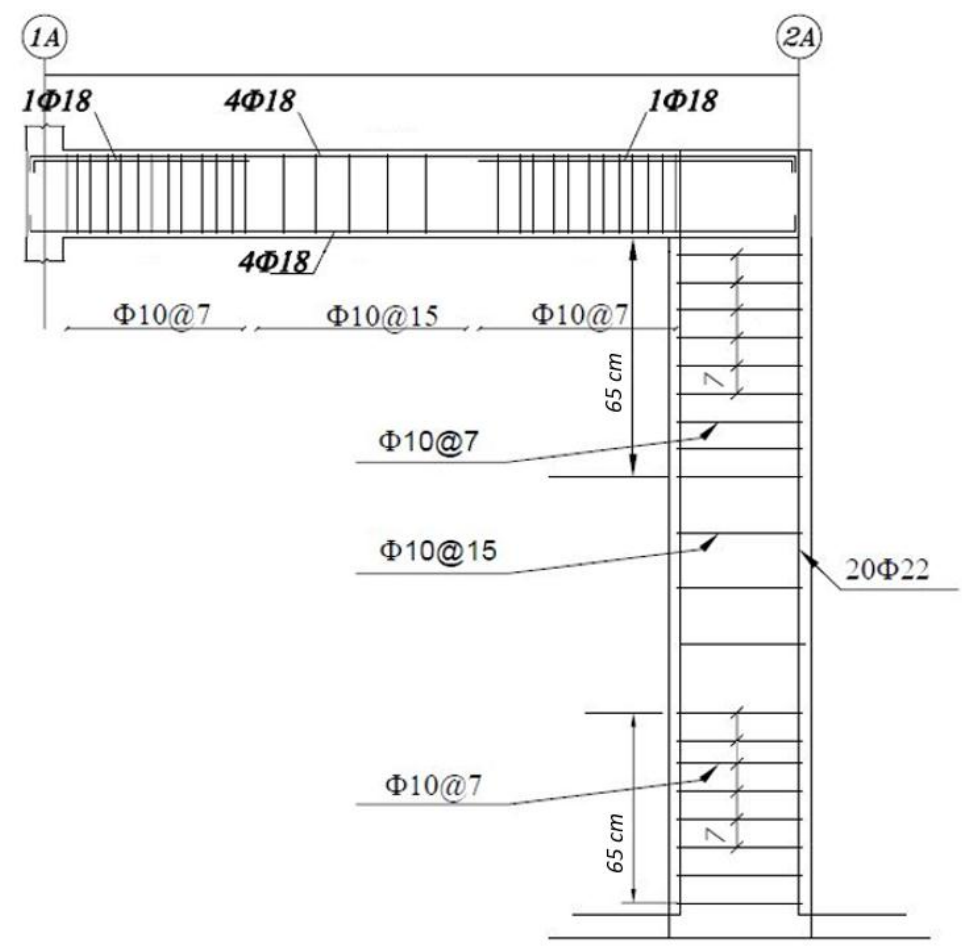

Fig 24. Details of designed RC connection

\subsection{RESULTS AND DISCUSSIONS OF NONLINEAR ANALYSIS OF RC CONNECTIONS}

Four RC connections have been designed and modelled in this section in order to investigate effects of the parameters on the behaviour of the connections subjected to the blast loading (Fig. 25). RC1 and RC2 are the designed RC connections for 5 and 9-storey buildings, respectively. RC3 is as the same as $\mathrm{RC} 1$, however, the stirrups space of the beam and column is halved. RC4 is also similar to RC1, while its beam has an increase of the cross-sectional size in its beam-column connection region so that the beam cross-section has been increased to $50 \times 55 \mathrm{~cm}$ in the beam-column region. Specifications of the RC1-RC4 connections are as the same as those described in the previous section.

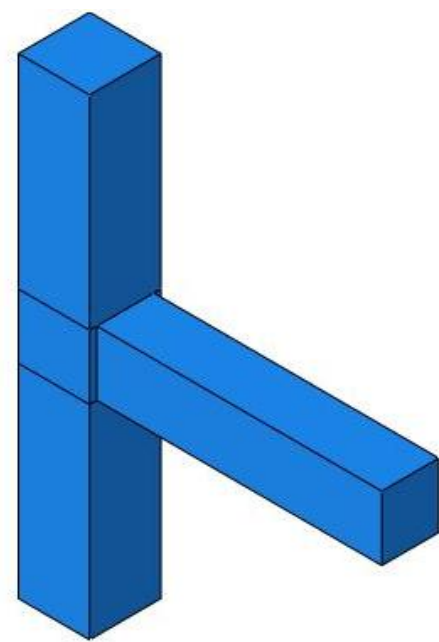

$\mathrm{RC} 1$ and $\mathrm{RC} 3$

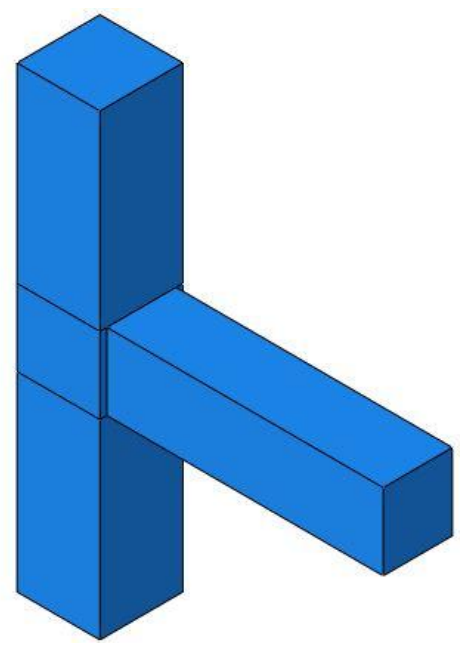

$\mathrm{RC} 2$

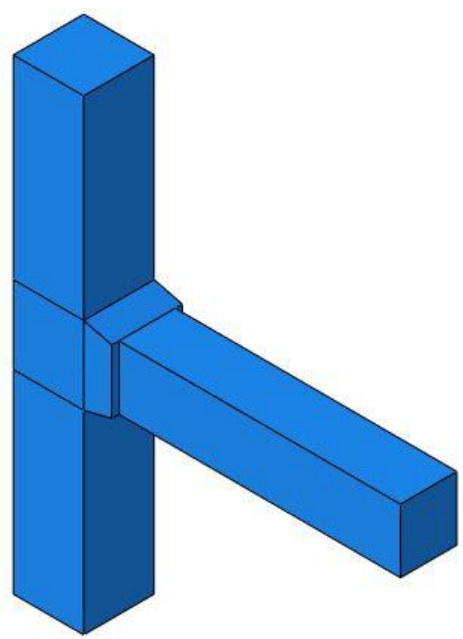

$\mathrm{RC} 4$

Fig 25. Modelled RC connections 


\subsubsection{Effect of Size of Cross-Section on RC Connections}

$\mathrm{RC} 1$ and RC2 have been subjected to the blast load of $1000 \mathrm{~kg}$ TNT at $5 \mathrm{~m}$ distance from them to examine the effect of crosssectional size on the connections. The obtained timedisplacement graphs of the beams end are demonstrated in Figs. 26-29 for RC1 and RC2 perpendicular to the blast load and in line with the blast load. Also, Table 9 lists the maximum displacements of the beams end of the connections caused by the blast of $1000 \mathrm{~kg}$ TNT at $5 \mathrm{~m}$ distance from them achieved from Figs. 26-29. The table indicates that the maximum displacements of the beam have occurred in line with the blast load for both RC1 and RC2. Nonetheless, the increase of the cross-sectional sizes of the beam and column has reduced these mentioned displacements for $40 \%$. Because the enhancement of the cross-sectional size of the beam and column results in the increase of the stiffness and moment of inertia of the connections which leads to the noticeable decrease of the displacements.

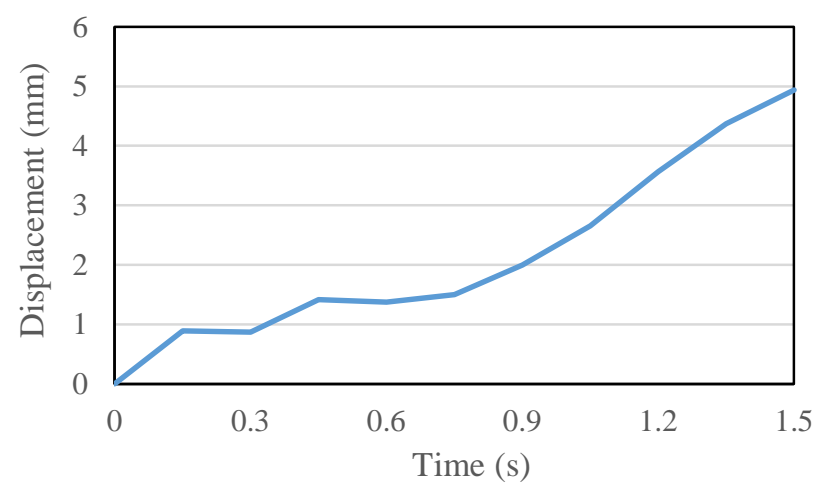

Fig 26. Displacement-time graph of RC1 beam end perpendicular to blast load

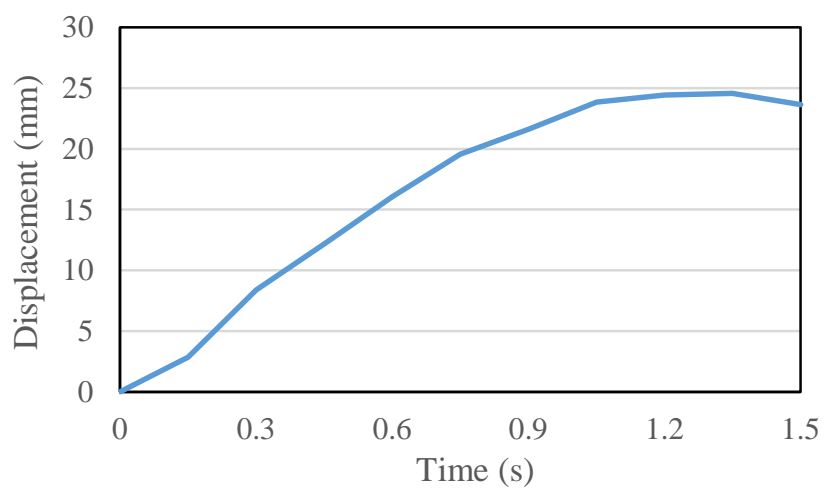

Fig 27. Displacement-time graph of RC1 beam end in line with blast load

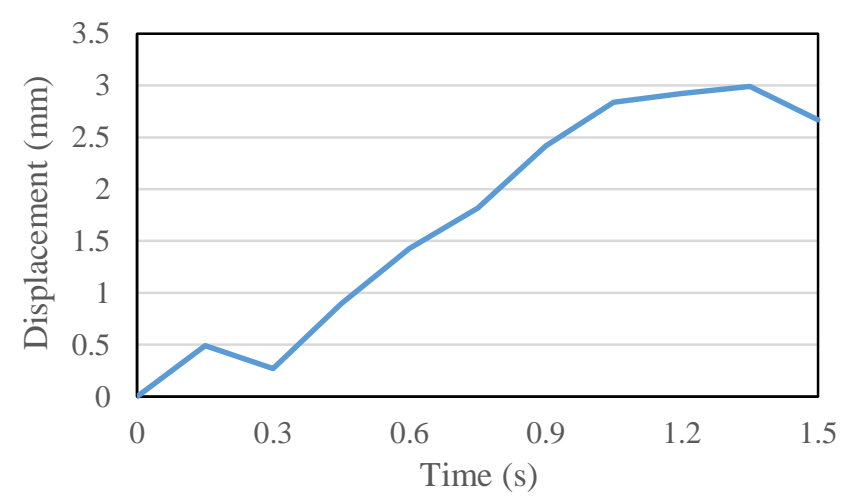

Fig 28. Displacement-time graph of RC2 beam end perpendicular to blast load

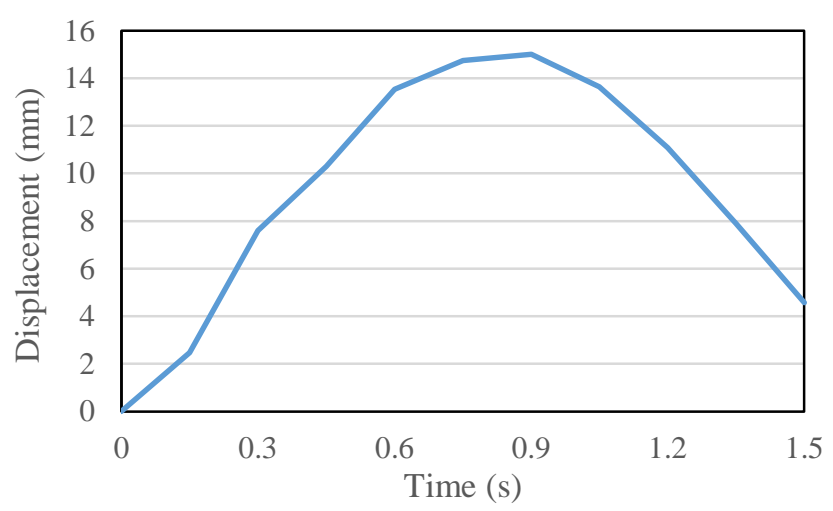

Fig. 29. Displacement-time graph of RC2 beam end in line with blast load

Table 9. Maximum displacement of beam end due to blast load

\begin{tabular}{|c|c|c|}
\hline Connection & $\begin{array}{c}\text { Displacement } \\
\text { perpendicular to blast } \\
\text { load (mm) }\end{array}$ & $\begin{array}{c}\text { Displacement in } \\
\text { line with blast } \\
\text { load (mm) }\end{array}$ \\
\hline RC1 & 5 & 25 \\
\hline RC2 & 3 & 15 \\
\hline
\end{tabular}

\subsubsection{Effect of Stirrups Space on RC Connections}

$\mathrm{RC} 1$ and $\mathrm{RC} 3$ have been considered against the blast load of $1000 \mathrm{~kg}$ TNT at the distance of $5 \mathrm{~m}$ from them to evaluate the effect of stirrups space on the connections. Figs. 30 and 31 respectively illustrate the displacement-time graphs of the beams end in line with the blast load and perpendicular to the blast load for RC3. As it is observed from Figs. 26-27 and Figs. 30-31, decreasing the spacing of the stirrups reduces the displacement of the beams end. For the ease of the data analysis, the maximum displacements obtained from the figures have been listed in Table 10. According to the figures and the table, it can be seen that the maximum displacement of the beam occurred in line with the blast load. Moreover, reducing the 
stirrups space decreases the displacement in line with the blast load and perpendicular to the blast load for $20 \%$ and $40 \%$, respectively. This issue is because of the point that decreasing the stirrups distance increases the stiffness of the connections components that leads to decrease of the displacement.

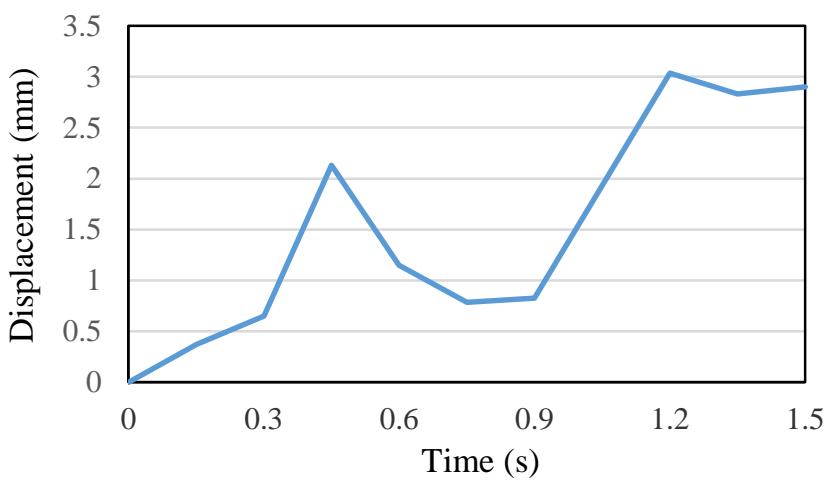

Fig 30. Displacement-time graph of RC3 beam end perpendicular to blast load

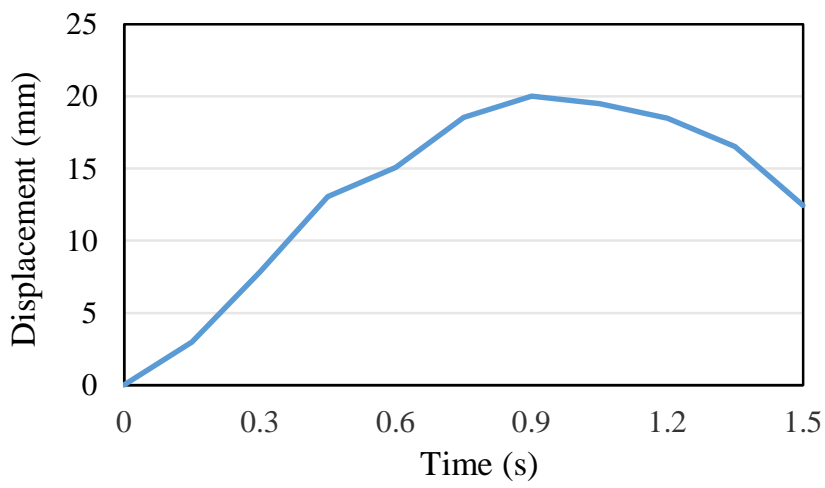

Fig 31. Displacement-time graph of RC3 beam end in line with blast load

Table 10. Maximum displacement of beam end due to blast load

\begin{tabular}{|c|c|c|}
\hline Connection & $\begin{array}{c}\text { Displacement } \\
\text { perpendicular to blast } \\
\text { load (mm) }\end{array}$ & $\begin{array}{c}\text { Displacement in } \\
\text { line with blast } \\
\text { load (mm) }\end{array}$ \\
\hline RC1 & 5 & 25 \\
\hline RC3 & 3 & 20 \\
\hline
\end{tabular}

\subsubsection{Effect of Making Beam Non-Prismatic in Beam- Column Connection Region}

To investigate the effect of making the beam non-prismatic on the connections, RC4 has been modelled against the blast load of $1000 \mathrm{~kg}$ TNT at $5 \mathrm{~m}$ distance. The displacement-time graphs obtained from the analysis of RC4 are illustrated in Figs. 32 and 33. Comparing Figs. 26-27 with Figs. 32-33 and their obtained corresponding maximum displacements in Table 11, it is resulted that making the beam non-prismatic in the beam- column connection region does not have significant effect on the displacement of the connections.

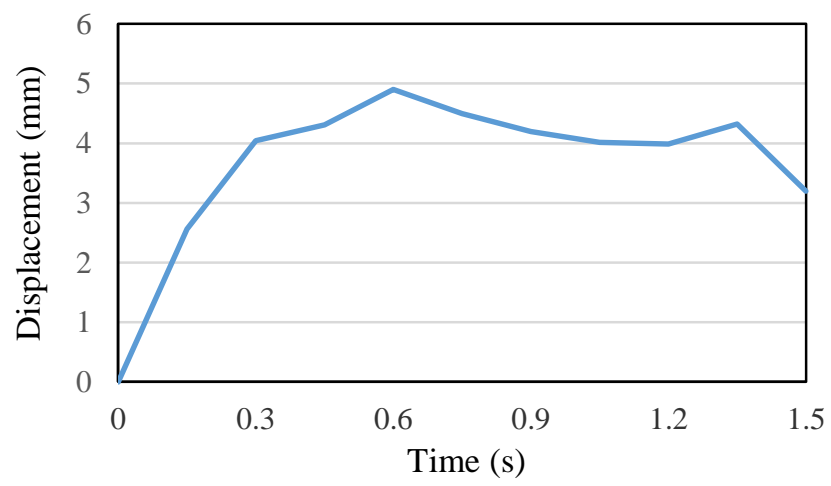

Fig 32. Displacement-time graph of RC4 beam end perpendicular to blast load

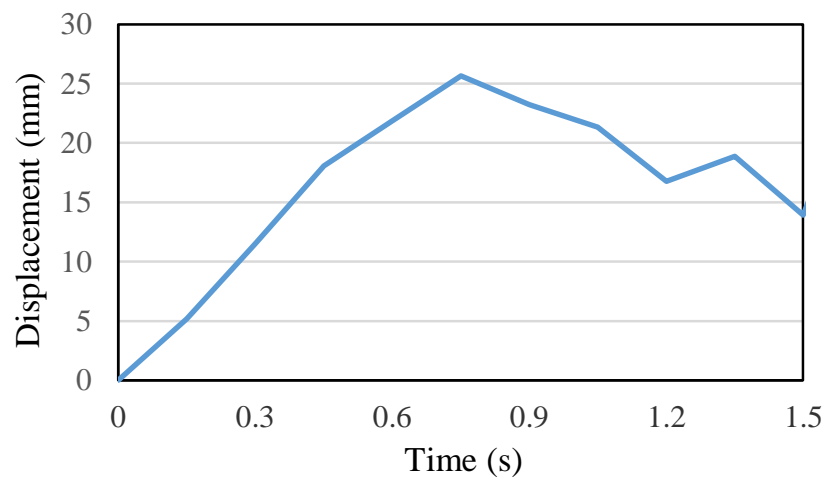

Fig 33. Displacement-time graph of RC4 beam end in line with blast load

Table 11. Maximum displacement of beam end due to blast load

\begin{tabular}{|c|c|c|}
\hline Connection & $\begin{array}{c}\text { Displacement } \\
\text { perpendicular to blast } \\
\text { load (mm) }\end{array}$ & $\begin{array}{c}\text { Displacement in } \\
\text { line with blast } \\
\text { load (mm) }\end{array}$ \\
\hline $\mathrm{RC} 1$ & 5 & 25 \\
\hline $\mathrm{RC} 4$ & 5 & 26 \\
\hline
\end{tabular}

\subsubsection{Failure Modes of RC Connections}

Fig. 34 indicates the failure modes of the RC connections subjected to the blast load. Comparing the failure modes of RC1 and RC2 shows that the stress concentration on the column in $\mathrm{RC} 1$ has been transferred to the beam and the beam-to-column connection in RC2 which is due to the use of the larger crosssections for the beam and column in RC2 in 9-storey building compared with RC1 in 5-storey building. Also, by comparison of the failure modes of RC3 and RC4 with that of RC1 it can be observed that the stress concentration on RC3 and RC4 is more 
on the beam and connection compared with $\mathrm{RC} 1$ which is a result of decreasing the stirrups spaces in $\mathrm{RC} 3$ and increasing the cross-sectional size of the beam in the connection region of RC4.

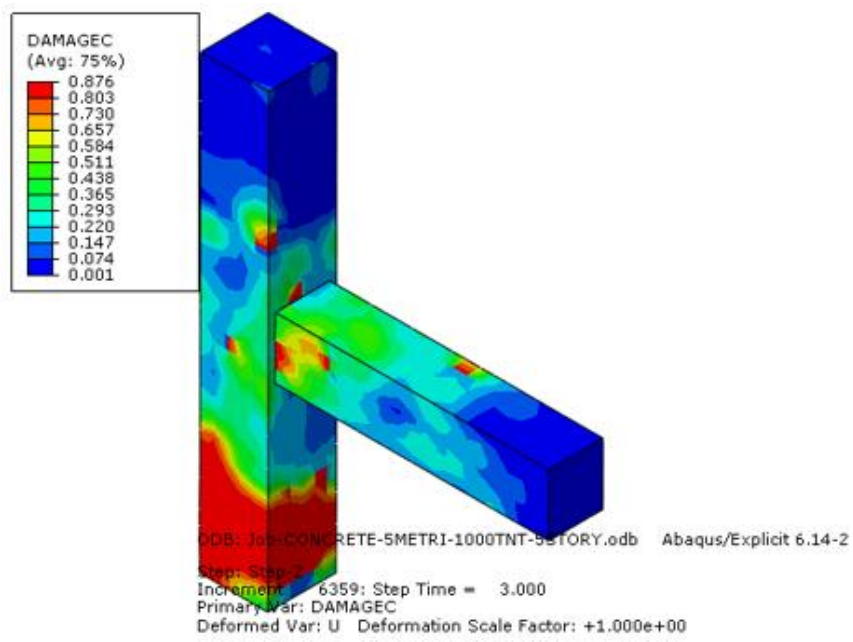

$\mathrm{RC} 1$
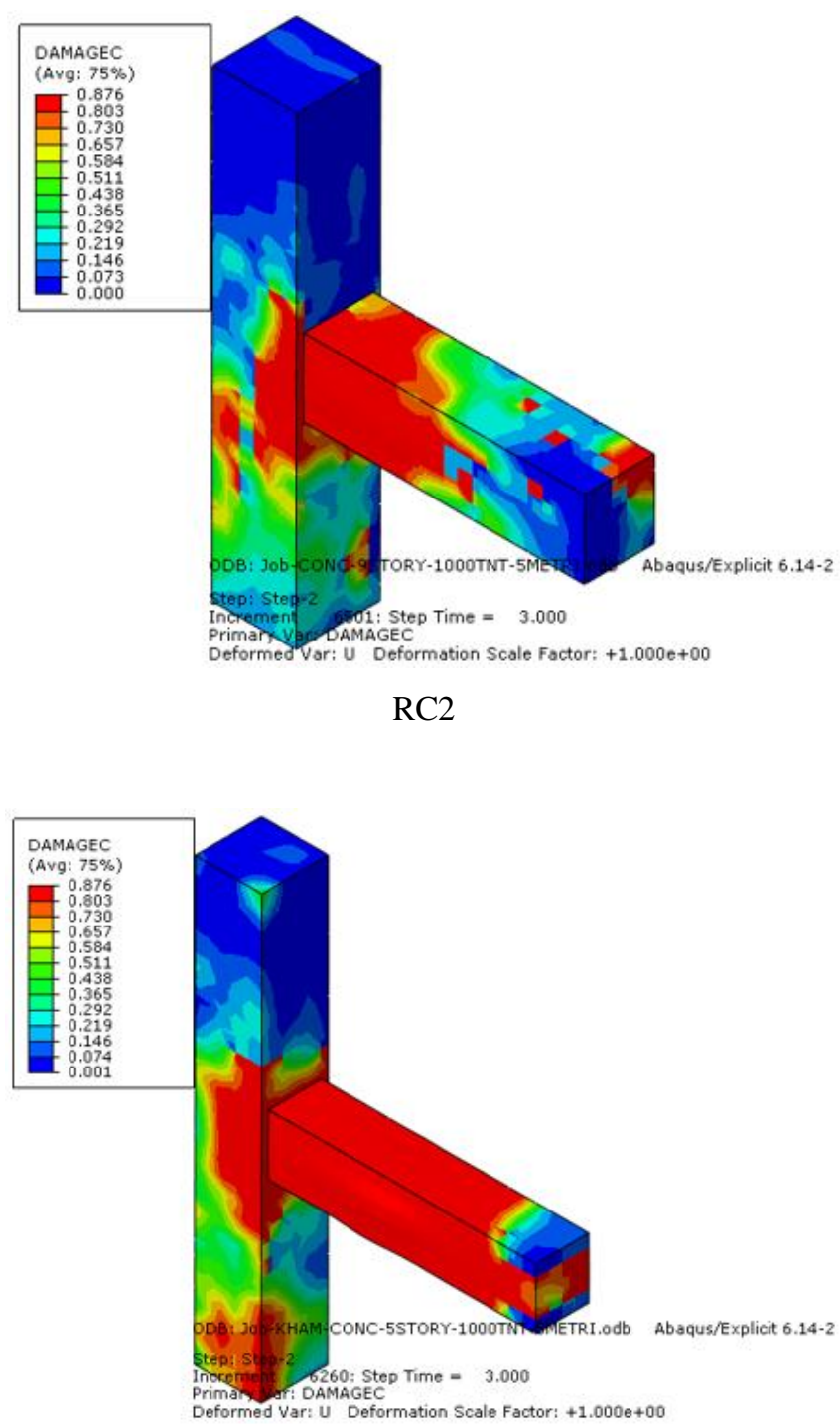

$\mathrm{RC} 3$

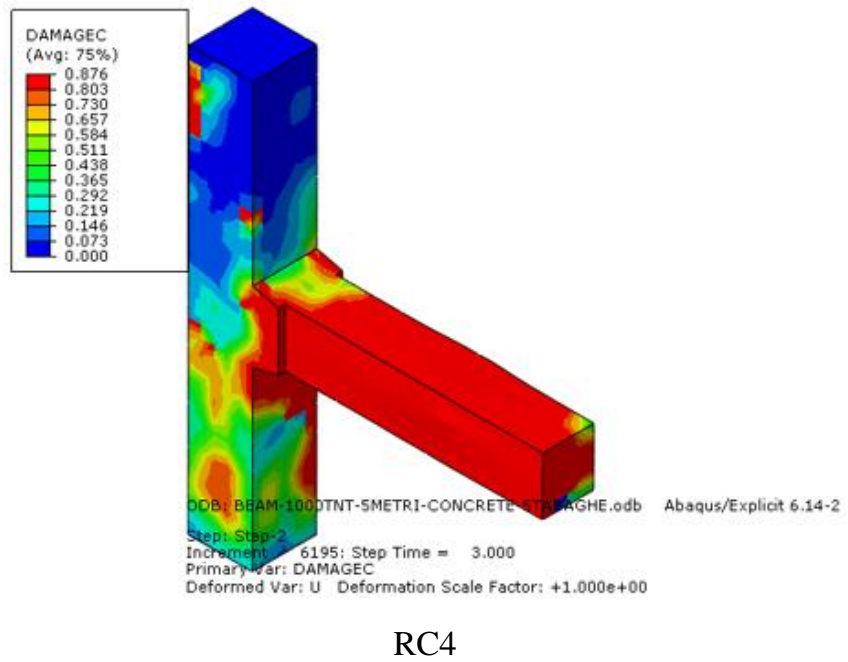

Fig 34. Failure modes of RC connections

\section{CONCLUSIONS}

The resistance of the blast-loaded steel and reinforced concrete beam-to-column connections was examined in this paper. The conclusions have been summarised in the following:

- The accuracy of the nonlinear FE modelling of steel and $\mathrm{RC}$ connections was verified by comparing the results of the FE modelling and experimental tests.

- In multi-storey steel and RC buildings, as the number of storeys increases, the size of the beams and columns enhances which significantly contributes to the resistance of the connections to the blast load.

- In the steel connections, the analysis indicated that the bolts arrangement has a considerable effect on the resistance of the connections to blast loading.

- Using stiffeners in the beams web of the steel connections and close to the connection region has no significant effect on the decrease of the connection displacement.

- Decreasing the stirrups space in the RC connections significantly reduces the displacement of the connection.

- Making the beam of the $\mathrm{RC}$ connection non-prismatic in the beam-column connection region does not remarkably influence the displacement of the connection.

- The stress concentration on the column of RC1 has largely been transferred to the beam of RC2, RC3, and $\mathrm{RC} 4$ which is our desired result. Because by transferring the stress concentration from the column to the beam of the blast-loaded buildings, the formation of the plastic hinge is transferred from the column to the beam and decreases the risk of the progressive collapse of the whole buildings which finally leads to the greater resistance of the building to the blast loading.

- By the comparison of the obtained results from the 
analyses of the steel and RC connections, it can be concluded that the displacements of the beams end in line with the blast load and perpendicular to the blast load for the steel connections are very larger than those for the RC connections. The larger displacements of the steel beam imply the higher ductility of the steel connections resulting in their more energy absorption and dissipation.

- In multi-storey steel buildings, there is less concern about the progressive collapse of the buildings subjected to the blast loading compared with RC buildings. This issue is because of the point that by increasing the number of storeys in buildings, larger cross-sectional sizes are resulted which in the case of the RC buildings lead to higher possibility of the brittle failure of the buildings and accordingly the risk of the sudden removal of the RC column increases that results in the higher risk of the progressive collapse of the RC buildings.

\section{REFERENCES}

[1] C. Kyei, "Effects of blast loading on seismically detailed reinforced concrete columns," Carleton University Ottawa, Ontario, 2014.

[2] S. Yao, D. Zhang, X. Chen, F. Lu and E. Wang, "Experimental and numerical study on the dynamic response of RC slabs under blast loading," Eng. Fail. Anal., vol. 66, pp. 120-129, 2016.

[3] J. Li, C. Wu, H. Hao, Z. Wang and Y. Su, "Experimental investigation of ultra-high performance concrete slabs under contact explosions," Int. J. Impact Eng., vol. 93, pp. 62-75, 2016.

[4] R. Khan, S. H. Farooq and M. Usman, "Blast loading response of reinforced concrete panels externally reinforced with steel strips," J. Infrastruct., vol. 4, doi:10.3390/infrastructures4030054, 2019.

[5] Y. Liu, J-b Yan and F-1 Huang, "Behavior of reinforced concrete beams and columns subjected to blast loading," Def. Tech., vol. 14, pp. 550-559, 2018.

[6] N. W. Hanson and H. W. Connor, "Seismic resistance of reinforced concrete beam-column joints," J. Struct. Div., vol. 93, no. 5, pp. 533-560, 1967.

[7] R. Park and T. Paulay, "Reinforced concrete structures," John Wiley \& sons, 1975.

[8] D. F. Meinheit and J. O. Jirsa, "Shear strength of RC beam-column connections," J. Struct. Div., vol. 107, pp. 2227-2244, 1981

[9] C. J. Oswald and E. J. Conarth, “A computer program for explosive damage assessment of conventional buildings”, U.S. Army Corps of Engineers, 1994.

[10] T. Krauthammer, "Blast-resistant structural concrete and steel connections," Int. J. Impact Eng., vol. 22, no. 9-10, pp. 887-910, 1999.
[11] J. M. LaFave, "Behavior and design of reinforced concrete beam-column connections with wide beams," Proceedings of the Structures Congress, American Society of Civil Engineers, Washington, D.C., United States, 2001.

[12] T. Sabuwala, D. Linzell and T. Krauthammer, "Finite element analysis of steel beam to column connections subjected to blast loads," Int. J. Impact Eng., vol. 31, pp. 861-876, 2005.

[13] M. P. Byfield, "Behavior and design of commercial multistory buildings subjected to blast," J. Perform. Construct. Fac., ASCE, vol. 20, no. 4, pp. 324-329, 2006.

[14] H. C. Yim, “A study of steel moment connections for structures under blast and progressive collapse loading rates," The Pennsylvania State University, Department of Civil and Environmental Engineering, 2007.

[15] C-C Chen and K-T Lin "Behavior and strength of steel reinforced concrete beam-column joints with two-side force inputs," J. Constr. Steel Res., vol. 65, no. 3, pp. 641-649, 2009.

[16] J. L. Liu, "Preventing progressive collapse through strengthening beam-to-column connection, part 1: theoretical analysis," J. Constr. Steel Res., vol. 66, no. 2, pp. 229-237, 2010.

[17] A. Heidarpour and M. A. Bradford, "Beam-column element for non-linear dynamic analysis of steel members subjected to blast loading," Eng. Struct., vol. 33, no. 4, pp. 1259-1266, 2011.

[18] I. Fadwa, T. A. Ali, E. Nazih and M. Sara, "Reinforced concrete wide and conventional beam-column connections subjected to lateral load," Eng. Struct., vol. 76, pp. 34-48, 2014.

[19] S. Khalate and S. Kulkarni, "Finite element analysis of cold formed steel bolted connection", Int. J. Recent Technol. Eng., vol. 4, no. 3, pp. 23-28, 2015.

[20] I. Faridmehr, Y. Ahmad, M. M. Tahir and M. H. Osman, "Cyclic and explosive evaluation of new proposed steel joint”, Adv. Civ. Eng., vol. 2016, article ID 4975097, 2016.

[21] M. A. Najafgholipour, S. M. Dehghan, A. Dooshabi and A. Niroomandi, "Finite element analysis of reinforced concrete beam-column connections with governing joint shear failure mode," Lat. Am. J. Solids and Stru., vol. 14, pp. 1200-1225, 2017.

[22] B. Yang, H. Wang, Y. Yang, S-B Kang, X-H Zhou and L. Wang, "Numerical study of rigid steel beam-column joints under impact loading", J. Constr. Steel Res., vol. 147, pp.62-73, 2018.

[23] F. F. Sun, X. Y. Xue, H. J. Jin, M. Sun, Z. M. Tang, Y. Xiao and G. Q. Li, "Hysteretic behavior and simplified simulation method of high-strength steel end-plate connections under cyclic loading", J. Constr. Steel Res., vol. 158, pp. 429-442, 2019. 
[24] B-O-B Sentosa, Q-B Bui, O. Ple, J-P Plassiard and P. Perrotin, "Assessing damage to beam-column connections in reinforced concrete structures from vibrational measurement results", Struct. Eng. Int., vol. 29, no. 3, pp. 396-403, 2019.

[25] E. P. Popov and S. M. Takhirov, "Bolted large seismic steel beam-to-column connections part 1: experimental study", Eng. Struct., vol. 24, pp.1523-1534, 2002.

[26] A. Bahrami, W. H. Wan Badaruzzaman and S. A. Osman, "Structural behaviour of tapered concrete-filled steel composite (TCFSC) columns subjected to eccentric loading”, Comput. Concrete, vol. 9, no. 6, pp. 403-426, 2012.

[27] A. Bahrami, W. H. Wan Badaruzzaman and S. A. Osman, "Investigation of concrete-filled steel composite (CFSC) stub columns with bar stiffeners", J. Civ. Eng. Manag., vol. 19, no. 3, pp. 433-446, 2013.
[28] A. Bahrami, W. H. Wan Badaruzzaman and S. A. Osman, "Behaviour of stiffened concrete-filled steel composite (CFSC) stub columns", Lat. Am. J. Solids Stru., vol. 10, no. 2, pp. 409-439, 2013.

[29] A. Bahrami and S. Matinrad, "Response of steel beamto-column bolted connections to blast loading", Int. J. Recent Technol. Eng., vol. 8, no. 3, pp. 3639-3648, 2019.

[30] A. Bahrami and M. Yavari, "Hysteretic assessment of steel-concrete composite shear walls", Int. J. Recent Technol. Eng., vol. 8, no. 2, pp. 5640-5645, 2019.

[31] S. S. Mahini and H. R. Ronagh, "Web-bonded FRPs for relocation of plastic hinges away from the column face in exterior RC joints," Compos. Struct., vol. 93, no. 10, pp. 2460-2472, 2011. 